\title{
PKM Pengembangan dan Pengolahan Produk Buah Naga di Kecamatan Samboja Kabupaten Kutai Kartanegara
}

\author{
Dragon Fruit Product Development and Processing in Samboja District, Kutai Kartanegara \\ Regency
}

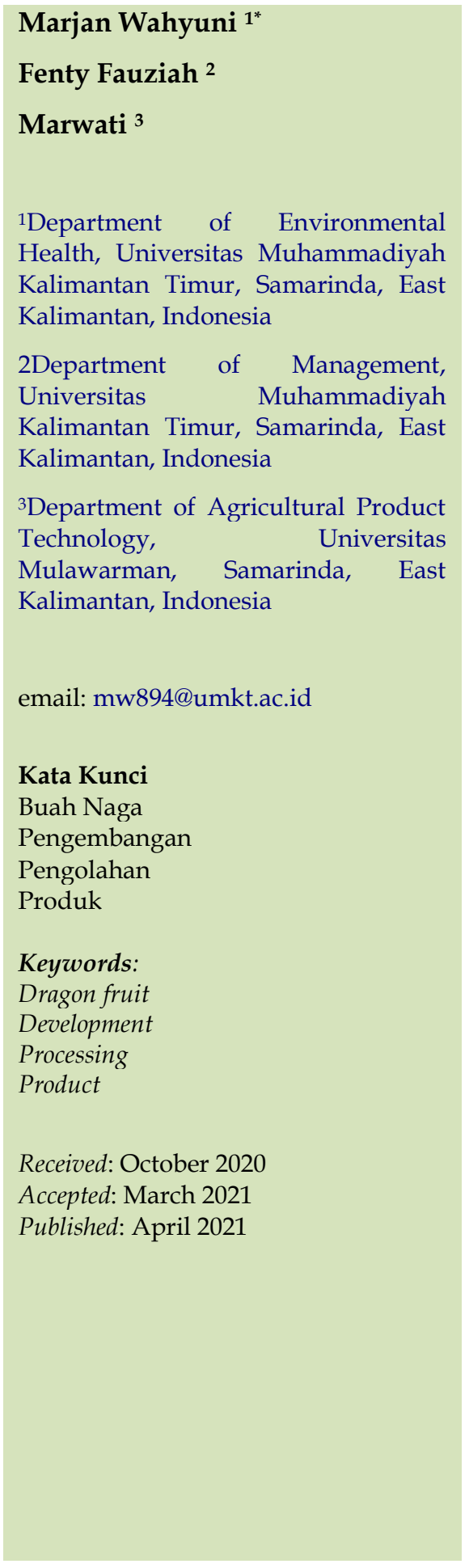

\begin{abstract}
Abstrak
Kecamatan Samboja yang terletak di Kabupaten Kutai Kartanegara memiliki potensi ekonomi yang cukup baik yaitu pembudidayan Buah naga. Petani buah naga di Kecamatan Samboja, khususnya anggota kelompok wanita tani di Kelurahan Sei Merdeka, menghadapi beberapa permasalahan yaitu petani merasa rugi, karena pada saat memasuki masa panen, buah naga diserang oleh hama tanaman. Buah naga yang hasilnya baik hanya sedikit dan dipasok oleh tengkulak yang sekaligus menjadi pembeli hasil panen dari buah naga tersebut. Hasil panen buah naga dari petani, dibeli oleh tengkulak dengan harga yang sangat murah dibandingkan dengan harga di pasaran. Di sisi lain, petani tidak mampu menjual sendiri buah naga secara langsung di supermarket maupun di pasar-pasar tradisional. Kegiatan PKM ini akan memberikan pelatihan tentang cara penanaman buah naga agar tidak diserang hama tanaman kepada mitra anggota kelompok wanita tani dan kelompok ibu PKK. Upaya ini dapat memutus ketergantungan dari anggota kelompok wanita tani terhadap tengkulak. Selain itu, kelompok ibu-ibu PKK yang menjadi mitra dalam kegiatan ini diberikan pengetahuan dan keterampilan untuk budidaya buah naga selanjutnya, hasil dari budidaya tersebut diolah menjadi berbagai produk pangan komersil, seperti mie, brownies selai, jelly dan sirup. Hasil dan luaran dari kegiatan PKM ini adalah peningkatan pengetahuan dan keterampilan dari anggota kelompok wanita tani dan ibu-ibu PKK dalam mengolah buah naga menjadi berbagai produk pangan olahan. Diharapkan juga akan tumbuh UMKM baru berbasis produk olahan buah naga.
\end{abstract}

\begin{abstract}
Samboja district in Kutai Kartanegara Regency has a fairly good economic potential: dragon fruit cultivation. Dragon fruit farmers in Samboja District, especially members of the women's farmer group in Sei Merdeka Village, face several problems. When they enter the harvest period, dragon fruit is attacked by plant pests. Dragon fruit is only a few and is supplied by middlemen who are also buyers of the dragon fruit harvest. Middlemen buy the dragon fruit at a meager price compared to market prices. On the other hand, farmers cannot sell dragon fruit themselves directly in supermarkets or in traditional markets. This PKM activity will provide training on how to plant dragon fruit, so that plant pests do not attack it to partner members of the women farmer groups and PKK women's groups. This effort can break the dependence of women farmer group members on middlemen. The PKK group of women who became partners in this activity was given knowledge and skills for further dragon fruit cultivation; the results of this cultivation were processed into various commercial food products, such as noodles, jam brownies, jelly, and syrup. The results and outputs of this PKM activity increase the knowledge and skills of members of the women farmer groups and PKK women in processing dragon fruit into various processed food products. It is also hoped that new MSMEs based on processed dragon fruit products will grow.
\end{abstract}




\section{PENDAHULUAN}

Kabupaten Kutai Kartanegara dengan luas wilaayah $27.263 \mathrm{~km}^{2}$, merupakan salah satu kabupaten di provinsi Kalimantan Timur. Kabupaten Kutai Kartanegara berbatasan dengan Kota Balikpapan di selatan, Kabupaten Kutai Barat di bagian Barat Serta Kota Samarinda dibagian tengah. Kabupaten Kutai Kartanegara terdiri atas 18 kecamatan, yang salah satu diantaranya adalah Kecamatan Samboja (Pemerintah Daerah Kabupaten Kutai Kartanegara, 2019).

Samboja merupakan sebuah kecamatan yang terletak di wilayah pesisir Kabupaten Kutai Kartanegara. Kecamatan Samboja menjadi kecamatan paling selatan yang berjarak $108 \mathrm{~km}$ dari pusat Kutai Kartanegara. Letaknya cukup strategis, karena berada dipesisir pantai dan menjadi tempat wisata di provinsi Kalimantan Timur. Kecamatan Samboja khususnya Kelurahan Sei Merdeka juga menjadi jalur transportasi yang sangat ramai menghubungkan kota Balikpapan dan Kota Samarinda. Lancarnya jalur transportasi ini, menjadi salah satu potensi yang menunjang perekonomian masyarakat di KecamatanSamboja, dengan luas wilayah $1.045 \mathrm{~km}^{2}$, yang terdiri dari 4 desa dan 18 kelurahan (Novianto \& Subandi, 2020).

Sebagian besar masyarakat Sei Merdeka memiliki usaha budidaya tanaman buah naga. Usaha budidaya buah naga, secara umum sudah mulai populer dibeberapa daerah dan Samboja terkenal sebagai penghasil buah naga. Namun 2 tahun terakhir produksi buah naga mulai mengalami penurunan, karena ada serangan hama terhadap buah naga tersebut yang menyebabkan harga jual menjadi turun. Harga buah naga yang awalnya sedikit lebih mahal hingga mencapai Rp. 30.000,- per kilogram akhirnya turun hingga mancapai Rp. 10.000,- per kilogram. Oleh sebab itu perlu pengetahuan dan keterampilan untuk menjaga kualitas buah dari serangan hama dan juga diperlukan produk olahan buah naga yang dapat dikomersilkan. Buah naga merupakan salah satu jenis buah yang kaya nutrisi dan bermanfaat bagi kesehatan (Irmayani et al., 2019; Yahya, 2017).

Tanaman buah naga merupakan salah satu produk hortikultura yang termasuk komoditas yang dikenal memiliki nilai ekonomi tinggi. Pada umumnya buah naga dinamakan sebagai pelepas dahaga karena memiliki kadar air yang sangat tinggi dan juga memiliki kadar gula 13-18 briks. Secara khusus buah naga juga dapat dimanfaatkan sebagai obat tradisional, yang memberikan banyak manfaat bagi kesehatan. Buah ini cukup kaya dengan berbagai zat vitamin dan mineral yang sangat membatu meningkatkan daya tahan tubuh dan bermanfaat bagi metabolisma dalam tubuh manusia karena adanya aktifitas antioksidan dari buah naga (Manihuruk et al., 2017). Noor et al. (2016) menyatakan bahwa kulit buah naga mengandung senyawa yang bermanfaat sebagai anti oksidan. Salah satu kandungan senyawa oksidan pada kulit buah naga adalah betalain dan antosianin. Manfaat buah naga bagi kesehatan dapat menjadi antioksidan seperti hasi1 penelitian Nurliyana et al. (2010) bahwa dalam setiap $\mathrm{mg} / \mathrm{ml}$ kulit buah naga dapat menghambat $83,48 \pm 1,02 \%$ radikal bebas dan daging buah naga dapat menghambat radikal bebas $27,45 \pm 5,03 \%$.

Banyak orang yang malas untuk mengonsumsi buah dalam keadaan utuh maupun buah potong, terutama anak-anak. Mereka lebih menyukai jus buah karena mengonsumi buah menjadi jauh lebih praktis. Oleh sebab itu perlu agar buah naga dapat dikonsumsi oleh semua kalangan dalam bentuk olahan buah naga. Berbagai keunggulan dari buah naga, merupakan suatu potensi besar untuk dikembang sebagai usaha besar produktif. Usaha budidaya buah naga ini sudah sangat dikenal, karena masyarakat tidak menjual langsung hasil panen buah naga ke pasar. Selama ini petani buah naga 
menjual hasil panen buah naga pada tengkulak dengan harga separuh dengan harga pasar (Syam, 2019). Berdasarkan hasil survey, harga penerimaan buah naga oleh pasar swalayan sebesar Rp. 45.000,- per kilogram. Namun buah naga dari petani dihargai oleh tengkulak hanya Rp. 5000,- hingga Rp. 10.000 per kilogram. Perbedaan yang sangat besar antara harga jual oleh tengkulak dengan harga yang diterima oleh petani membuat petani menjadi frustasi dan enggan untuk tidak serius menjalani usaha ini. Beberapa petani telah berusaha untuk menjual langsung hasil panennya di pasar swalayan, namun pihak swalayan menolak dan hanya mau menerima produk dari tengkulak (Andriani et al., 2019). Kondisi ini semakin sulit karena keterbatasan pengetahuan dan teknologi produksi bibit. Para petani buah naga hanya bisa mendapat buah naga dari tengkulak tersebut.

Tingginya ketergantungan terhadap tengkulak dalam pemasaran dan adanya serangan hama pada saat mendekati musim panen menyebabkan produksi berkurang dan harga buah naga melonjak, sehingga perlu segera diatasi. Upaya yang dapat dilakukan adalah penyediaan alat untuk melindungi buah naga dari serangan hama pada saat memasuki masa panen. Kemudian mengolah sendiri buah naga menjadi pangan yang bermanfaat dan disenangi oleh masyarakat. Selanjutnya, kelompok ibu-ibu PKK dari Kelurahan Sei Merdeka dan Kelompok Wanita Tani yang memiliki semangat tinggi untuk berwirausaha, diberikan bekal keterampilan untuk mengolah buah naga menjadi berbagai produk pangan komersil yang telah popular dan disenangi oleh masyarakat, seperti mie, brownies, selai, jelly, dan sirup.

Menurut Chayati et al. (2011), buah naga memiliki berbagai keunggulan, antara lain lebih fleksibel pemanfaatannya untuk diolah menjadi berbagai produk pangan dengan beragam bentuk dan citarasa, masa simpannya lebih lama, serta lebih praktis dalam proses distribusi. Upaya ini perlu mendapat dukungan berupa bantuan teknologi dan pembinaan proses produksi dan pemasaran, hingga masyarakat menjadi mandiri dalam menjalankan usahanya. Keberhasilan usaha ini dapat menjadi sumber pendapatan serta dapat menningkatkan kesejahteraan masyarakat.

\section{METODOLOGI}

Metode kegiatan pengabdian dilaksanakan dengan fokus grup diskusi dan metode pelatihan untuk meningkatkan pengetahuan. Rencana kegiatan pengabdian PKM di Kecamatan Samboja Kabupaten Kutai Kartanegara, dibagi dalam 10 tahap, yaitu:

1. Tahap ke-1.

Diseminasi dan sosialisasi rencana pengabdian masyarakat dengan pemerintah desa, tokoh masyarakat dan mitra.

2. Tahap ke-2.

Pengenalan dan pelatihan cara melindungi buah naga dari serangan hama. Pengenalan alat untuk melindungi buah naga dari serangan hama. Kondisi yang dipersyaratkan dalam perlindungan, hingga buah naga siap panen. Pelatihan dilakukan dengan cara peserta mempraktekan langsung semua tahap yang dilakukan, dengan memanfaatkan kantong yang digunakan untuk membungkus buah naga.

3. Tahap ke-3.

Pendampingan proses budidaya buah naga. Pendampingan pada tahap ini untuk memsatikan bahwa proses budidaya dan perawatan buah naga dilakukan dengan benar. Pada tahap ini dilakukan evaluasi hasil pada setiap frekuensi panen.

4. Tahap ke-4.

Pengenalan dan pelatihan teknologi pengolahan buah naga. Teknologi penepungan diperkenalkan sebagai upaya untuk meningatkan efektifitas dan 
efisiensi produksi. Pelatihan diberikan terkait teknik pembuatan buah naga. Pelatihan diberikan disertai dengan praktek oleh masyarakat untuk memastikan bahwa masyarakat telah memahami dan terampil dalam memproduksi buah naga.

\section{Tahap ke-5.}

Pendampingan proses produksi buah naga. Pendampingan dilakukan untuk mendapatkan kepastian bahwa proses produksi buah naga telah dilaksanakan sesuai prosedur yang diberikan pada pelatihan pendampingan dan juga dilakukan identifikasi masalah dan dilakukan langkah-langkah penyelesaian masalah.

6. Tahap ke-6.

Pelatihan pembuatan aneka produk pangan berbasis buah naga. Pelatihan diberikan pada kelompok ibuibu rumah tangga seperti pembuatan mie, brownies, selai, jelly, dan sirup. Pelatihan disertai dengan praktek oleh peserta untuk memastikan bahwa peserta telah memahami dan terampil dalam memproduksi berbagai produk pangan yang terbuat dari buah naga.

7. Tahap ke-7.

Pendampingan pembuatan kemasan produk. Pendampingan dilakukan untuk membuat berbagai desain kemasan yang aman dan menarik.

8. Tahap ke-8.

Pelatihan manajemen keuangan dan pemasaran. Mitra diberikan pelatihan tentang manajemen keuangan dan pendampingan penyusunan pembukuan serta pendampingan dilakukan untuk membantu dalam teknik pemasaran baik secara langsung, maupun melalui media online.

9. Tahap ke-9.

Pendampingan pengurusan administrasi. Pendampingan dilakukan untuk membantu mitra dalam proses pendaftaran UMKM baru di Dinas
Perindustrian Kabupaten Kutai Kertanegara, pendaftaran P-IRT, pelatihan Sistim Jaminan Halal.

10. Tahap ke-10.

Evaluasi hasil kegiatan pengabdian yang telah dilaksanakan.

\section{HASIL DAN PEMBAHASAN}

Kegiatan pengabdian dilaksanakan dalam beberapa tahap yang diawali dengan tim pengabdi melakukan survei lokasi dan mengidentifikasi kegiatan ibu-ibu yang bergabung dalam Kelompok Wanita Tani (KWT) dan kelompok PKK di KecamatanSamboja Kabupaten Kutai Kartanegara. Identifikasi dilakukan dengan metode tanya jawab. Berdasarkan hasil tanya jawab, ada beberapa permasalahan yang dialami peserta kelompok ibu-ibu yang tergabung dalam KWT dan penggerak PKK diantaranya:

1. Sebanyak $70 \%$ ibu-ibu KWT dan PKK menyatakan sudah pernah melakukan pengolahan buah naga menjadi produk/industri, tetapi tidak berlangsung lama.

2. Pengalaman ibu-ibu tim penggerak PKK dalam pengolahan buah naga masih sangat terbatas.

3. Dengan adanya pandemi, penghasilan ibu-ibu menjadi sangat menurun, sedangkan biaya produksi sangat tinggi.

4. Keterbatasan ibu-ibu dalam pemasaran hasil produksi, karena belum memiliki PIRT/izin edar dari Dinas Kesehatan.

5. Kemasan produk yang masih sangat minim sehingga mengalami kesulitan dalam pemasaran.

Hasil wawancara tersebut menjadi tahap awal bagi tim pengabdi untuk memberikan materi sesuai dengan kebutuhan mitra/peserta pelatihan. Hal ini dilakukan agar peserta memperoleh materi yang pas dan sesuai dengan kebutuhan mitra.

Peserta yang hadir dalam pelaksanaan program 
pegabdian kepada masyarakat berjumlah 22 orang yang terdiri dari 10 orang tim penggerak PKK dan 12 orang peserta dari KWT. Peserta yang hadir sangat antusias dan aktif selama pelatihan yang berlangsung 2 hari. Keaktifan peserta tampak dari partisipasi aktif pada saat sesi tanya jawab dan penugasan sebagai bentuk tanggapan positif dari berbagai materi yang dipaparkan. Acara dilaksanakan pada hari jumat dan sabtu, tanggal 11-12 September 2020. Kegiatan pelatihan dan pendampingan tersebut dilaksanakan di Aula KWT Samboja.

Pengabdian dilaksanakan selama 2 hari, pada hari pertama ibu-ibu diberikan materi tentang cara pengembangan dan pengolahan produk berbasis buah naga (mie basah dan kering buah naga, selai buah naga, sirup buah naga, yogurt buah naga, dan es krim buah naga). Selain cara pengolahan buah naga, ibu-ibu juga diberikan materi tentang kewirausahaan dan cara pembukuan, sehingga mereka dapat menganalisis biaya dalam produksi. Pembukuan juga sangat penting menurut pendapat ibu-ibu, karena selama produksi mereka selalu menggabungkan antara uang belanja dan uang hasil jualannya. Pada sesi terakhir dihari pertama, peserta diberikan materi tentang pentingnya pengurusan PIRT sebagai syarat untuk izin edar produk industry rumah tangga. Setelah materi tentang PIRT, ibuibu didampingi untuk mengisi formular pengajuan izin edar/PIRT yang langsung dipandu oleh ketua KWT yang telah berpengalaman.

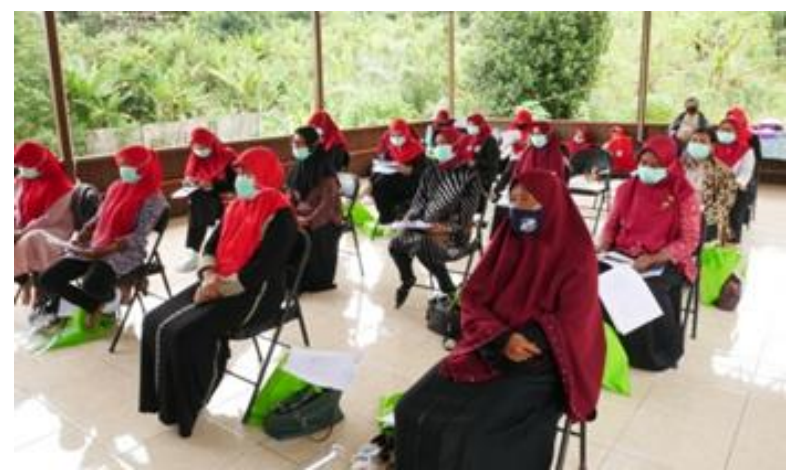

Gambar 1. Pelatihan Penogahan Produk buah Naga
Materi dihari kedua adalah memperkenalkan kepada peserta tentang pentingnya produk halal dan cara pengurusan sertifikat halal produk ke LPPOM MUI Kalimantan Timur. Peserta sangat antusias dengan materi tersebut, karena inilah yang menjadi salah satu kendala bagi mereka untuk menjual produk keluar daerah. Hari kedua ini, peserta sekaligus didampingi membuat pembukuan sederhana dan melakukan praktek pengolahan produk berbasis buah naga. Pada pembuatan produk buah naga, ibu dibagi kelompok sesuai dengan wilayah tempat tinggalnya. Maksud pembagian ini untuk memudahkan ibu-ibu tersebut melakukan produksi secara berkelompok.
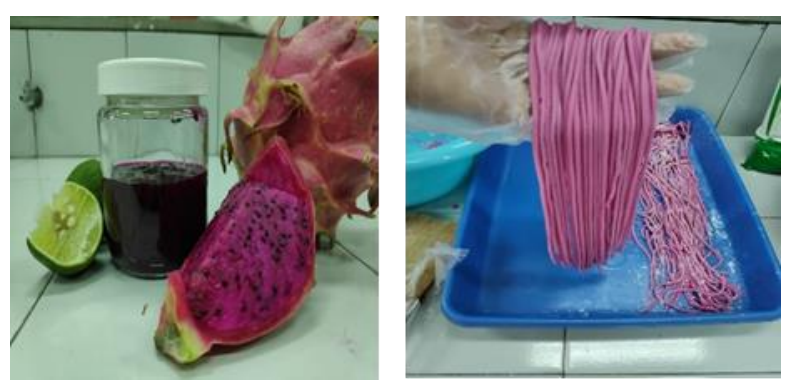

Gambar 2. Hasil Olahan Produk buah Naga berupa selai (kiri) dan mie (kanan)

Pada gambar 2 diatas adalah merupakan hasil dari beberapa olahan produk buah naga berupa selai buah naga dan mie buah naga. Produk yang dihasilkan setelah praktek langsung bisa dinikmati oleh peserta, sehingga mereka sangat tertarik untuk mengolah buah yang ada di sekeliling mereka. Sebelum adanya program pengabdian masyarakat, peserta hanya membuat produk berupa dodol dan stik buah naga, sehingga pangsa pasar juga sangat terbatas. Dengan adanya produk baru dari hasil pengabdian masyarakat, merupakan hasil kreasi baru berbahan buah naga. Produkini pun merupakan produk kesukaan anak-anak dan remaja era milenial.

Kegiatan pengabdian berjalan lancar, karena ibu-ibu peserta sangat antusias, juga didukung fasilitas yang disiapkan oleh KWT berupa microphone, sound system dan 
LCD. Secara teknis kegiatan tersebut tidak menemukan hambatan, namun karena ada beberapa fasilitas yang kurang sehingga hasil produksi yogurt dan es krim harus menunggu 24 jam kemudian. Selain itu masalah pandemi covid-19, sehingga waktu sangat terbatas untuk bersosialisasi dengan peserta, sehingga tim pengabdian masyarakat harus menunggu beberapa waktu untuk dapat melaksanakan kegiatan ini.

\section{KESIMPULAN}

Kegiatan PKM ini akan memberikan pelatihan kepada mitra anggota kelompok wanita tani dan kelompok ibu PKK tentang cara penanaman buah naga agar tidak diserang hama. Selain itu, kelompok ibu-ibu PKK yang menjadi mitra dalam kegiatan ini diberikan pengetahuan dan keterampilan untuk budidaya buah naga selanjutnya. Hasil dari budidaya tersebut diolah menjadi berbagai produk pangan komersil, seperti mie, brownies, selai, jelly dan sirup, agar memberikan nilai yang lebih maksimal dari pada dijual langsung. Hasil dan luaran dari kegiatan PKM ini adalah peningkatan pengetahuan dan keterampilan dari anggota kelompok wanita tani dan ibu-ibu PKK dalam mengolah buah naga menjadi berbagai produk pangan olahan yang halal, sehat dan higienis serta modul pengolahan produk berbasis buah naga. Implikasi kegiatan ini juga diharapkan akan tumbuh UMKM baru berbasis produk olahan buah naga.

\section{UCAPAN TERIMA KASIH}

Terima kasih disampaikan kepada Direktur Pendidikan Tinggi, Kementerian Pendidikan dan Kebudayaan Republik Indonesia yang telah memberikan kesempatan pada tim pengabdi untuk melakukan kegiatan pengabdian ini melalui dana hibah penelitian dan pengabdian pada masyarakat tahun anggaran 2019. Ucapan terima kasih juga kepada ketua PKK Kelurahan
Sungai Merdeka dan Ketua KWT yang telah banyak membantu pelaksanaan pengabdian masyarakat serta pada seluruh ibu-ibu peserta yang sangat antusias. Kepada ketua LPPM UMKT dan seluruh staf LPPM yang telah banyak membantu proses pelaksanaan dan pelaporan kami ucapkan banyak terima kasih.

\section{REFERENSI}

Andriani, R., Rasmikayati, E., Mukti, G.W., Fatimah, S. 2019. Faktor-faktor yang Mempengaruhi Keputusan Petani Mangga dalam Pemilihan Pasar di Kabupaten Indramayu. Jurnal Penyuluhan. 15(2):286-298. https://doi.org/10.25015/penyuluhan.v15i2. 27736

Chayati, I., Ratnaningsih, N., Widi, T.H. 2011. Teknologi Pengolahan Buah Naga Dan Diversifikasi Produk Olahannya Sebagai Upaya Peningkatan Jiwa Kewirausahaan di SMK Agri Industri. INOTEKS: Jurnal Inovasi Ilmu Pengetahuan, Teknologi, dan Seni. 15(2):182-195.

Irmayani, I., Purnama, D., Arman, A., Ilmi, N. 2019. Strategi Pengembangan Komoditi Lokal Buah Naga berbasis Agribisnis di Kabupaten Soppeng. Agrikan: Jurnal Agribisnis Perikanan. 12(1):126-135. https://doi.org/10.29239/j.agrikan.12.1.126135

Manihuruk, F.M., Suryati, T., Arief, I.I. 2017. Effectiveness of the Red Dragon Fruit (Hylocereus polyrhizus) Peel Extract as the Colorant, Antioxidant, and Antimicrobial on Beef Sausage. Tropical Animal Science Journal. 40(1):47-54. https://doi.org/10.5398/medpet.2017.40.1.47

Noor, M.I., Yufita, E., Zulfalina. 2016. Identification Content of the Red Dragon Fruit Extract Skin Using Fourier Transform Infrared (FTIR) and Phytochemistry. Journal of Aceh Physics Society. 5(1):14-16.

Novianto, E., Subandi, M. 2020. Kemiskinan di Daerah Kaya Sumber Daya Alam (Studi Kasus Kecamatan Samboja Kabupaten Kutai Kartanegara). Jurnal Penelitian Kesejahteraan Sosial. 19(1):63-75. http://dx.doi.org/10.31105/jpks.v19i1.1963 
Nurliyana, R., Zahir, I.S., Suleiman, K.M., Aisyah, M.R., Rahim, K.K. 2010. Antioxidant study of pulps and peels of dragon fruits: a comparative study. International Food Research Journal. 17:367-375.

Pemerintah Daerah Kabupaten Kutai Kartanegara. 2019. Profil Kecamatan Samboja Kabupaten Kutai Kartanegara.

http://kabupaten.kutaikartanegara.com/kec amatan.php?k=Samboja

Syam, S. 2019. Strategi Pengembangan Usaha Pada Komoditas Buah Naga Di Kabupaten Sinjai. Jurnal Ekonomika. 3(2):43-51. https://doi.org/10.37541/ekonomika.v3i2.25 2

Yahya, H. 2017. Analisis Kandungan Vitamin C pada Buah Naga yang Diperjualbelikan Di Sekitar Kota Makassar. Media Laboran: Jurnal Analis Kesehatan. 7(1):20-23. 